Copyright (C) 2020 by Academic Publishing House Researcher

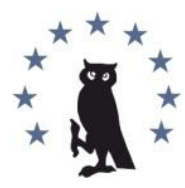

Published in the Russian Federation

European Researcher. Series A

Has been issued since 2010.

E-ISSN 2224-0136

2020, 11(1): 10-19

DOI: 10.13187/er.2020.1.10

www.erjournal.ru

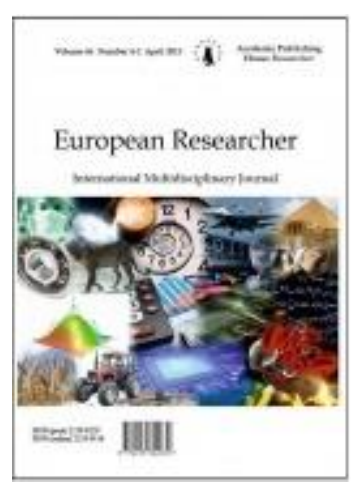

\title{
The Study of the Levels of Perception of Audiovisual Media Texts of Interethnic Issues in the Student Audience
}

Irina Chelysheva a, *

a Rostov State Economic University, Russian Federation

\begin{abstract}
The article presents the results of an experimental study of the levels of perception of audiovisual media texts of interethnic problems in a student audience. The author presents the main theoretical approaches to this problem, identifies key classification indicators for the perception of audiovisual media texts, and analyzes diagnostic material on the study of the levels of media perception of audiovisual media texts on ethnic issues.

The main methodological principles of the research are: the principle of the unity of theory and practice in the study of the problem of interethnic tolerance.

Keywords: interethnic tolerance, media education, media perception, university students, experimental research.

\section{1. Введение}

Межэтническая толерантность представляет собой важное профессиональное качество студентов - будущих педагогов. В ее основе лежит умение адекватно оценивать учеников вне зависимости от национальной принадлежности, уважать национальную культуру обучающихся, проявлять терпение, выдержку, самообладание. Кроме того, будущему педагогу необходимо знать и учитывать индивидуальные особенности каждого ребенка, проблемы в отношениях между детьми и их причины, этнокультурные особенности социального окружения ребенка. В современной педагогической науке существует целый ряд методов, способствующих развитию навыков толерантного поведения. Использование методов воспитывающей ситуации, социальной пробы, рефлексии и другие позволяют активизировать интерес студенческой молодежи к проблемам толерантности, необходимости ведения конструктивного диалога на основе взаимного уважения и взаимопонимания.
\end{abstract}

В числе актуальных проблем развития межэтнической толерантности выступает построение целостной концепции и стратегии поликультурных принципов учебновоспитательного процесса. Как отмечает Г.Ж. Фахрутдинова, до настоящего времени в числе нерешенных вопросов остаются проблемы «лицензирования и аккредитации национальных образовательных учреждений, в новом профессиональном стандарте отсутствует перечень компетенций, отражающих поликультурную грамотность будущих педагогов» (Фахрутдинова, 2017: 5).

\footnotetext{
${ }^{*}$ Corresponding author

E-mail addresses: ivchelysheva@yandex.ru (I. Chelysheva)
} 
В современных информационных условиях к числу важнейших компетенций студентов - будущих педагогов относится медиакомпетентность, выступающая результатом медиаобразования, которое, в свою очередь, как известно, «является частью основных прав каждого гражданина любой страны мира на свободу самовыражения и права на информацию и является инструментом поддержки демократии» (Recommendations Addressed..., 1999: 273-274).

Медиаобразование выступает важным фактором становления личности. Среди его основных задач - «развитие критического и аналитического мышления, формирование нравственных установок, ценностных ориентаций, мировоззренческих позиций посредством общения с произведениями медиакультуры и т.д. Данные принципы, основанные на взаимопонимании, конструктивном диалоге, взаимном уважении и сотрудничестве представителей разных национальностей и этносов, взаимопринятии традиций и культурных ценностей в условиях культурного многообразия выступают основными содержательными компонентами межэтнической толерантности» (Челышева, 2019).

Умение осуществлять анализ и интерпретацию произведений медиакультуры становится очень важным в условиях интенсификации информационного потока, который мы наблюдаем последние годы. Можно согласимся с мнением Н.В. Чичериной о том, что «являясь знаковым окном в мир, расширяющим границы мира индивида, медиатекст одновременно устанавливает пределы познания той реальности, которая не дана ему непосредственно, поскольку заложенная в него система смыслов основана на предварительном выборе того, что станет объектом интерпретации, а что нет. Именно поэтому особую важность приобретает формирование навыков и умений медиаграмотности и овладение способами интерпретативного анализа медиатекстов (Чичерина, 2007).

В самом деле, медиавосприятие, то есть «восприятие «медиареальности», чувств и мыслей авторов медиатекстов» (Федоров, 2010) выступает одним из ключевых понятий медиаобразования. Совершенно справедливым в этой связи является мнение А.В.Федорова о том, что «анализируя зарубежные и отечественные труды, посвященные проблемам медиа и медиаобразования, можно обнаружить немало общего в структуре различных моделей и методик. Но до того, как перейти к их анализу, необходимо разобраться в вопросах, связанных с проблемой медиавосприятия, оценки, развития молодежной аудитории. Ибо, не проанализировав эту проблему, нельзя сориентировать медиаобразовательную модель на конкретные возрастные, психологические и иные особенности аудитории» (Федоров, 2004). В связи с этим, в контексте данного исследования выдвигается задача представить результаты исследования уровней восприятия аудиовизуальных медиатекстов межэтнической проблематики в современной студенческой аудитории.

\section{2. Материалы и методы}

Методологическую базу исследовательского проекта составляют теоретические положения диалога культур М.М. Бахтина - В.С. Библера, исследования Ю. Лотман, М. Маклюэна, П. Сорокина,Н.А.Бердяева, Н. Лумана, В.А. Ядова и др. Как свидетельствует теоретический анализ проблемы (Челышева, 2019), важное значение для данного исследования имеют труды ведущих российских и западных медиапедагогов: А.В. Федорова, Н.Ф. Хилько, Л. Мастермана, Б. Бахмайера, Д. Букингема, Дж. Брайант и С. Томпсона, Д. Рашкоффа, Н. Андерсена, Дж. Пандженте и О. Мэлли и др.

Основным материалом данной статьи выступает экспериментальная работа, направленная на диагностику уровней восприятия аудиовизуальных медиатекстов межэтнической проблематики в студенческой аудитории. Основными методологическими принципами исследования выступают: принцип единства теории и практики в исследовании проблемы межэтнической толерантности.

Методы исследования: анализ и синтез научных источников по проблеме исследования, обобщение и классификация, эксперимент.

\section{3. Обсуждение}

Последние десятилетия проблематика межэтнической толерантности студенческой молодежи рассматривается в целом ряде педагогических исследований отечественных авторов. Например, одним из первых исследований в этой области в постсоветский период 
стало диссертационное исследование О.И. Пономаревой, где были представлены процессы формирования этнопедагогической культуры студентов-будущих педагогов (Пономарева, 1999) в поликультурном социуме. Позже, в работах В.А. Виниченко (Виниченко, 2011), А.В. Федорова (Федоров, 2007), Н.Ф. Хилько (Хилько, 2013), И.В. Челышевой (Челышева, 2019), И.В.Челышевой и Г.В.Михалёвой (Chelysheva, Mikhaleva, 2019) и др. был частично представлен анализ медиаобразовательного потенциала в процессе развития толерантности личности. Киноискусство как средство воспитания толерантности рассматривается в исследованиях Е.Ю. Жмыровой (Жмырова, 2008). Т.И. Чечет (Чечет, 2014) посвятила свое исследование комплексному подходу к личностным проблемам формирования критического мышления и толерантности современного при обучении иностранным языкам, в том числе - и на материалах масс-медиа.

Как показал проведенный теоретический анализ, наиболее развернутую характеристику показателей медиавосприятия, которая лежит в основе данного эмпирического исследования, выдвинул профессор А.В. Федоров (Федоров, 2004). В качестве основных критериев медиавосприятия были выделены следующие:

1. Целостность восприятия медиатекста;

2. Эмоциональная реакция в восприятии медиатекста

3. Интеллектуальная активность в восприятии медиатекста;

4. Волевая реакция в восприятии медиатекста;

5. Проявление индивидуальности в выборе медиатекста.

Уровни данных показателей могут быть различными. Характеристика данных уровней представлена А.В. Федоровым следующим образом:

1. Уровень первичной идентификации (варианты: низкий, фабульный, элементарный, наивно-реалистический, примитивный, фрагментарный). Эмоциональная, психологическая связь с медиасредой, фабулой (цепью событий) повествования, то есть способность воспринимать цепь событий в медиатексте (к примеру, отдельные эпизоды и сцены фабулы), наивное отождествление действительности с содержанием медиатекста, ассимиляция среды (эмоциональное освоение реальности, представленной в медиатексте и т.п.);

2. Уровень вторичной идентификации (варианты: средний, сюжетносинтаксический). Отождествление с персонажем медиатекста. То есть способность сопереживать, поставить себя на место героя (ведущего), понимать его психологию, мотивы поступков, восприятие отдельных компонентов медиаобраза (деталь и т.д.);

3. Уровень комплексной идентификации (варианты: высокий, авторскоконцептуальный, системный, адекватный). Отождествление с автором медиатекста при сохранении первичной и вторичной идентификации (с последующей интерпретацией увиденного). То есть способность соотнесения с авторской позицией, что позволяет предугадать ход событий медиатекста на основе эмоционально-смыслового соотнесения элементов сюжета, восприятия авторской мысли в динамике звукозрительного образа, синтеза мыслей и чувств зрителя в образных обобщения.

\section{4. Результаты}

Целью эксперимент работы являлось исследование уровней восприятия студентами аудиовизуальных медиатекстов межэтнической проблематики.

Для достижения поставленной цели применялись следующие методы исследования: беседы, методика «Незаконченные предложения», наблюдение. В экспериментальной работе приняли участие 100 студентов Ростовского государственного экономического университета (факультет психологии и социальной педагогики).

Подробную характеристику основных показателей соответствующих высокому, среднему и низкому уровню восприятия аудиовизуальных медиатекстов межэтнической проблематики мы представили в Таблице 1. 
Таблица 1. Характеристика показателей медиавосприятия аудиовизуальных медиатекстов межэтнической проблематики

\begin{tabular}{|c|c|c|c|}
\hline Показатели & Высокий уровень & Средний уровень & Низкий уровень \\
\hline $\begin{array}{l}\text { Целостность } \\
\text { восприятия } \\
\text { медиатекста }\end{array}$ & $\begin{array}{lr}\text { Студент без } & \text { труда } \\
\text { анализирует } & \\
\text { аудиовизуальный } & \\
\text { медиатекст, } & \text { способен } \\
\text { осмыслить } & \text { пвторскую } \\
\text { позицю } & \end{array}$ & $\begin{array}{l}\text { Студент способен } \\
\text { проанализировать } \\
\text { содержание } \\
\text { медиатекста, с } \\
\text { помощью педагога } \\
\text { определить главную } \\
\text { мысль }\end{array}$ & $\begin{array}{l}\text { Студент } \quad \text { способен } \\
\text { проанализировать только } \\
\text { содержание медиатекста }\end{array}$ \\
\hline $\begin{array}{l}\text { Әмоциональная } \\
\text { реакция } \\
\text { восприятии } \\
\text { медиатекста }\end{array}$ & $\begin{array}{l}\text { анализируя } \\
\text { медиапроизведение, } \\
\text { употребляет оценочные } \\
\text { эпитеты, высказывает свое } \\
\text { эмоциональное отношение } \\
\text { к медиатексту }\end{array}$ & $\begin{array}{l}\text { при анализе } \\
\text { употребляет незна- } \\
\text { чительное } \\
\text { количество } \\
\text { эмоционально- } \\
\text { оценочных } \\
\text { эпитетов, } \\
\text { затрудняется } \\
\text { высказать свое } \\
\text { отношение к } \\
\text { медиатексту }\end{array}$ & 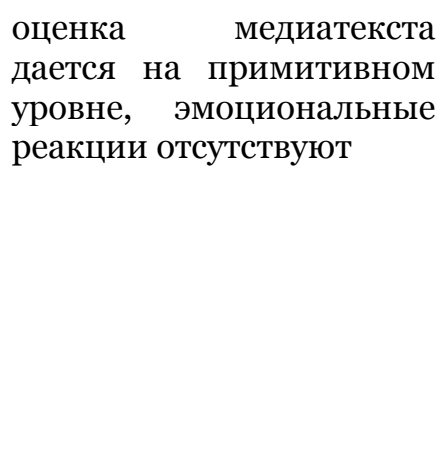 \\
\hline $\begin{array}{l}\text { Интеллектуальная } \\
\text { активность } \\
\text { восприятии } \\
\text { медиатекста }\end{array}$ & $\begin{array}{l}\text { старается подробно } \\
\text { изложить доказательства, } \\
\text { использует обобщения }\end{array}$ & $\begin{array}{l}\text { есть отдельные } \\
\text { моменты анализа, } \\
\text { но в большей } \\
\text { степени анализ } \\
\text { носит } \\
\text { описательный } \\
\text { характер }\end{array}$ & $\begin{array}{l}\text { анализ описательный, } \\
\text { бездоказательный, при } \\
\text { ответе на } \\
\text { опирается нопросы } \\
\text { мнение }\end{array}$ \\
\hline $\begin{array}{l}\text { Волевая реакция в } \\
\text { восприятии } \\
\text { медиатекста }\end{array}$ & $\begin{array}{l}\text { проявляет активность, } \\
\text { интерес к обсуждаемой } \\
\text { теме медиатекста }\end{array}$ & $\begin{array}{l}\text { отвечает после } \\
\text { некоторого } \\
\text { раздумья, иногда с } \\
\text { неохотой; в } \\
\text { процессе } \\
\text { выполнения задает } \\
\text { вопросы }\end{array}$ & $\begin{array}{l}\text { не проявляет особого } \\
\text { желания и активности, не } \\
\text { проявляет интереса к } \\
\text { обсуждаемой теме }\end{array}$ \\
\hline $\begin{array}{l}\text { Проявление } \\
\text { индивидуальности в } \\
\text { выборе медиатекста }\end{array}$ & $\begin{array}{l}\text { выбор медиатекста студент } \\
\text { производит } \\
\text { самостоятельно, может } \\
\text { аргументировать его }\end{array}$ & $\begin{array}{l}\text { выбор } \\
\text { медиатекста } \\
\text { осуществляет без } \\
\text { посторонней } \\
\text { помощи, но } \\
\text { аргументацию } \\
\text { своего выбора } \\
\text { провести } \\
\text { затрудняется }\end{array}$ & $\begin{array}{l}\text { студент не может } \\
\text { самостоятельно выбрать } \\
\text { понравившийся } \\
\text { медиатекст (советуется с } \\
\text { товарищами, педагогом). } \\
\text { Аргументировать свой } \\
\text { выбор не может }\end{array}$ \\
\hline
\end{tabular}

С целью выявления уровней восприятия по основным показателям, студентам было предложено вспомнить и назвать игровые фильмы, связанные с межэтнической и межнациональной проблематикой, выбрать один из наиболее понравившихся аудиовизуальных медиатекстов, а затем в процессе устного опроса ответить на следующие вопросы:

- объяснить выбор определенного аудиовизуального медиатекста;

- подробно описать собственное отношение к данному произведению медиакультуры, а также к проблеме, которой он посвящен. 
Как показал анализ проведенного опроса, большая часть студентов (64 \%) выбрала развлекательные медиатексты, среди которых было особенно много фильмов комедийного жанра: «Моя большая греческая свадьба» (реж. Д. Цвик, Канада, США, 2001); «Индийский ковбой» (реж. N. Kamkolkar, США, 2004); разные части фильма «Такси» (реж. Жерар Пире, Франция, 1998), «Дружить по-русски» (реж. В. Суджян, Франция, 2019) и т.д. К основным мотивам выбора медиатекстов развлекательных жанров студенты отнесли захватывающий сюжет, участие в фильмах известных актеров и т.п.

Среди фильмов более серьезного характера, студентами были названы следующие кинокартины: «Столкновение» (реж. П. Хаггис, США, Германия, 2004); «Мальчик в полосатой пижаме» (реж. М.Херман, Великобритания, 2008); «Список Шиндлера» (реж. С. Спилберг, США, 1993); «Пианист» (реж. Р. Полански, Польша, Франция, Великобритания, Германия, 2002) и др. Среди мотивов выбора данных медиатекстов студенческой аудиторией были выделены следующие: психологические и социальные проблемы, поднимаемые в фильмах; события, связанные с историческими событиями, межличностными отношениями представителей разных народов и этносов; мировоззренческие, нравственные проблемы и т.п. Как нам представляется, интерес к данным медиапроизведениям вполне соответствует возрастным особенностям студенческой возрастной группы: студенты всерьез задумываются над вопросами нравственного выбора, мировоззренческими проблемами, социальной активности. В связи с этим, положительноэмоциональное отношение, которое студенты проявляют к тем произведениям аудиовизуальной медиакультуры, где рассматриваются проблемы межличностных отношений представителей разных национальностей и культур, вполне ожидаемы.

Вместе с тем, проведенный опрос позволил заключить, что студенты проявляют интерес в основном, к аудиовизуальным произведениям западного производства: хорошо знают актеров, режиссеров известных блокбастеров. Исключения составляют лишь российские фильмы и сериалы, вышедшие совсем недавно. Среди них - комедийные сериалы «Кухня» (реж. Д. Дьяченко, Г. Крыжовников, А. Федотов, Россия, 2012-2016); «Последний из Магикян» (реж. Р. Гигинеишвили, А. Сахелашвили, Россия, 2013-2016), «Дружба народов» (реж. Ш. Муслимов, Россия, 2013). В основном, среди причин выбора данных медиатекстов, студентами назывались участие известных актеров, которые снимались в телевизионных сериалах. Вместе с тем, с творчеством отечественных режиссеров студенты знакомы не очень хорошо.

На следующем этапе диагностической работы аудитории была предложена методика «Незаконченные предложения». Студентам было предложено закончить следующие предложения:

1. Когда вы смотрите новый фильм, сериал, где затронуты межнациональные и межэтнические проблемы то ...

a) можете без труда рассказать, какая идея была заложена автором (создателем) того или иного медиатекста;

б) вы понимаете мотивы поступков героев, но главную идею автора вам определить достаточно трудно;

в) можете лишь описать основные события сюжета.

2. После того, как вы посмотрели фильм, сериал межэтнической проблематики ...

a) можете без труда самостоятельно оценить медиатекст, долго размышляете над судьбой героев;

б) можете сказать, хороший фильм (игра) или плохой, о героях помнишь недолго;

в) не задумываетесь над просмотренным медиатекстом, за героев не переживаете.

3. Если вам предложено написать эссе (рецензию) на тему просмотренного фильма на межнациональную тему, то вы...:

a) с удовольствием самостоятельно выполните задание, постараетесь подробно изложить свои мысли и доводы;

б) беретесь за работу только по необходимости, прибегаете к помощи интернетисточников, так как испытываете трудности в изложении своих мыслей;

в) изначально решаете для себя, что без посторонней помощи вам с заданием не справиться. 
4. Если вы видели интересный фильм, сериал по теме межнациональных отношений, то...:

а) обязательно обсуждаете увиденное на экране с друзьями, с семьей, можете ответить на вопросы, без стеснения высказываете свое мнение, можете доказать его;

б) не особенно любите, когда вас спрашивают об увиденном, своими впечатлениями делитесь только с близкими друзьями и в большинстве случаев полагаетесь на их мнение;

в) предпочитаете ни с кем не обсуждать увиденное, так как это занятие лишено смысла.

5. Если Вам предстоит выбрать фильм по межэтнической проблематике, то ...:

а) будете делать это самостоятельно, сможете объяснить свой выбор;

б) выбираете фильм самостоятельно, рассчитывая на вою интуицию. Чем привлек медиатекст ваше внимание, сказать трудно;

в) чаще всего выбираете по совету друзей или по отзывам в Интернете.

Каждое предложение методики соответствует определенному показателю восприятия аудиовизуальных медиатекстов. Ответы респондентов оценивались следующим образом: вариант «а» (2 балла) соответствовал высокому уровню по данному показателю, вариант «б» (1 балл) - среднему, и вариант «в» (о баллов) - низкому уровню восприятия аудиовизуальных медиатекстов по отдельно взятому показателю.

Анализ работ студентов показал следующее.

Среди выбранных вариантов в предложении 1, при помощи которого уточнялся уровень по показателю «целостное восприятие аудиовизуального медиатекста», удалось выявить, что очень немногие студенты (25\%) демонстрируют высокий уровень. Данные студенты признали, что без особого труда могут проанализировать медиатекст межэтнической проблематики, раскрывая авторскую позицию. Большинство студентов (57\%) признали, что способны в какой-то мере проанализировать содержание, то есть описать то, что происходит на экране, сопровождая это своими комментариями. Остальные студенты (18\%) продемонстрировали низкий уровень по первому показателю, то есть ответили, что могут без труда лишь описать содержание событий медиатекста.

Анализ предложения 2 был направлен на уточнение сведений по показателю эмоциональной реакции в момент восприятия аудиовизуального медиатекста, где затронуты межэтнические и межнациональные отношения. Ответы респондентов на вопросы методики (а также во время проведенного опроса, описанного нами выше) показали, что студенты проявляют неоднозначную эмоциональную реакцию. Так, на высоком уровне по данному показателю находятся 32 \% студентов, которые, анализируя медиапроизведение, употребляют оценочные эпитеты, без особого труда высказывают свое отношение к событиям, актерской игре. Значительная часть респондентов находится на среднем уровне: 50 \% студентов, хоть и употребляют при анализе незначительное количество оценочных эпитетов, но часто затрудняются высказать свое личное отношение к произведению аудиовизуальной медиакультуры. 28 \% опрошенных продемонстрировали низкий уровень по данному показателю, проявляя равнодушное отношение к персонажам и происходящим событиям.

Третье предложение методики было предложено студентам с целью выявления уровня по показателю интеллектуальной активности в момент анализа аудиовизуального медиатекста на межнациональную тему. Полученные данные позволили заключить, что у $36 \%$ респондентов анализ произведения киноискусства носит описательный характер. Только 19 \% студентов самостоятельно и подробно могут изложить свои доказательства, делают попытки обобщить высказанное мнение. Эти данные подтвердило наблюдение за студентами во время устного опроса, когда происходил выбор наиболее предпочтительных медиатекстов.

Предложение 4 раскрывало сущность показателя волевой реакции в момент анализа аудиовизуального медиатекста по теме межнациональных отношений. Сравнив полученные в ходе опроса с данными методики, мы пришли к выводу о том, что многие респонденты довольно активно приступают к обсуждению произведений аудиовизуальной медиакультуры межэтнической проблематики, с желанием и интересом участвуют в обсуждении. Как нам кажется, это может свидетельствовать об активном интересе студенческой аудитории к аудиовизуальным медиатекстам по проблемам межэтнических и межнациональных отношений. 
При помощи пятого предложения методики уточнялись полученные сведения о таком показателе как проявление индивидуальности при выборе аудиовизуального медиатекста межэтнической проблематики. Анализ ответов респондентов и сравнение их с устными мнениями во время опроса позволил заключить, что высокий уровень по данному показателю демонстрируют 30 \% студентов: они без особых затруднений могут мотивировать свой выбор. Средний уровень по данному показателю выявлен у 39 \% студентов. Эта группа выбор аудиовизуального медиатекста осуществляет самостоятельно, но аргументацию своего выбора провести затрудняется. Существенные затруднения в самостоятельном выборе аудиовизуального медиатекста предложенной тематики продемонстрировали 31 \% респондентов. Дарнный показатель, как нам представляется во многом связан с тем, что большинство молодых людей при выборе того или иного фильма для просмотра, ориентируются как правило, на отзывы в интернете, не уделяя внимания тому, кто является создателем фильма, на каких событиях основан сюжет и т.д.

Так как в процессе исследования нам было необходимо выявить общий уровень восприятия аудиовизуальных произведений аудиовизуальной медиакультуры межэтнической проблематики, обобщение полученных результатов проводилось следующим образом. Наибольшее количество баллов, набранных каждым респондентом по результатам проведенного опроса, наблюдения и методики «Незаконченных предложений» равно 10 баллам, наименьшее - о баллов. Таким образом, группа «высокого уровня» объединяет аудиторию, чьи показатели в основном находятся на высоком и среднем уровнях. Для них характерны высокий уровень эмоциональной отзывчивости и интеллектуальной активности при восприятии аудиовизуальных медиатекстов межэтнической проблематики. Остальные показатели могут быть близки к обозначенному высокому уровню или находиться на среднем уровне. Сумма баллов, набранных студентами данной группы, колеблются от 8 до 10 баллов. У респондентов группы «среднего уровня» показатели могут быть разбросаны по всем трем уровням, но чаще всего держатся на среднем. Сумма набранных баллов - от 5 до 7.

Группа студентов с низким уровнем восприятия аудиовизуальных медиатекстов межэнической проблематики характеризуется следующим образом: практически все показатели находятся на уровнях не выше низкого и среднего уровня. В сумме студенты, попавшие в данную группу, имеют менее 5 баллов.

Таким образом, проведенное исследование уровней восприятия аудиовизуальных медиатекстов межэтнической проблематики показало следующее: на низком уровне находятся 40 \% респондентов, средний уровень оказался у 37 \% студентов; высокий уровень продемонстрировали 23 \% студентов, принявших участие в экспериментальной работе.

\section{5. Заключение}

Итак, по результатам проведенного экспериментального этапа исследования можно сделать следующие выводы:

- в основном, студенты продемонстрировали средний и низкий уровень медиавосприятия по выделенным показателям, соответствующие уровню первичной и вторичной идентификации;

- у многих студентов, принявших участие в экспериментальной работе прослеживается устойчивая эмоциональная, психологическая связь с медиасредой, фабулой (цепью событий) повествования (соответствующая низкому, фабульному уровню медиавосприятия). Они без труда воспринимают и воспроизводят цепь событий в медиатексте межэтнической проблематики (пересказывают отдельные эпизоды или очередность основных событий);

- попытки осуществить анализ аудиовизуального медитекста студентами показали, что у значительной части респондентов можно обнаружить отождествление с персонажами медиатекста (соответствующее среднему уровню развития медиавосприятия). Многие студенты сопереживают главным героям фильма, пытаются поставить себя на место героя, предпринимают попытки понять его психологию, мотивы поступков, демонстрируют восприятие отдельных компонентов медиаобраза;

- на уровне комплексной идентификации, соответствующему высокому уровню медиавосприятия по результатам констатирующего эксперимента, оказалась незначительная часть респондентов. Лишь немногие студенты (23\%) способны 
интерпретировать основную идею, замысел авторов аудиовизуального медиатекста межэтнической проблематики на основе эмоционально-смыслового соотнесения элементов сюжета, синтезировать свои мысли и чувства в образных обобщениях;

- к особенностям восприятия аудиовизуальных произведений у экспериментальной группы можно отнести предпочтение медиатекстов развлекательного характера медиатектов западного производства. При интересе, проявляемом к аудиовизуальным медиатекстам в целом, не все студенты отдают предпочтение серьезным и познавательным медиатекстам;

- в ходе экспериментальной работы было выявлено, что у студентов имеются достаточно устойчивые медиапредпочтения, довольно хорошие знания о медиапроизведениях зарубежного производства, им хорошо знакомы актеры и режиссеры известных блокбастеров. Знания о российских аудиовизуальных медиатекстах (в частности фильмах и сериалах), ограничиваются у большинства респондентов фамилиями известных актеров, которые снимаются в телевизионных сериалах;

- в процессе экспериментальной работы было выявлено, что у многих студентов недостаточно развиты аналитические навыки оценки аудиовизуальных медиатекстов межэтнической проблематики, самостоятельность и аргументация при выборе медиапроизведений находится в большинстве случаев на недостаточно высоком уровне.

- в целом, студенты проявляют достаточно активный интерес к аудиовизуальным медиатекстам межэтнической проблематики, где рассматриваются мировоззренческие, нравственные проблемы. Наиболее положительно-эмоциональное отношение студенты проявляют к тем произведениям аудиовизуальной медиакультуры, где рассматриваются проблемы межличностных межнациональных отношений. При этом не все студенты демонстрируют целостность медиавосприятия аудиовизуальных медиатекстов.

\section{6. Благодарности}

Статья написана при финансовой поддержке Российского фонда фундаментальный исследований (РФФИ) в рамках научного проекта № 19-013-о0о3о «Отражение проблемы межэтнической толерантности студенческой молодежи в российском и англоязычном медиаобразовании постсоветского периода (1992-2020)», выполняемого в Ростовском государственном экономическом университете. Руководитель проекта - к.п.н., доцент И.В. Челышева.

\section{Литература}

Виниченко, 2011 - Виниченко В.А. Формирование межэтнической толерантности у будущих специалистов по связям с общественностью. Автореф. .... дис. к.п.н. Иркутск: Северо-Восточный федеральный университет, 2011. 20 с.

Жмырова, 2008 - Жмырова Е.Ю. Киноискусство как средство воспитания толерантности у учащейся молодежи // Тамбовский университет. Серия: Гуманитарные науки, 2008. 3 (59): 303-306. [Electronic resource]. URL: https://cyberleninka.ru/ article/n/kino iskusstvo-kak-sredstvo-vospitaniya-tolerantnosti

Пономарёва, 1999 - Пономарёва О.И. Формирование основ этнопедагогической культуры будущего учителя в поликультурном социуме. Автореф. .... дис. к.П.н. М., 1999. 23 с.

Фахрутдинова, 2017 - Фахрутдинова Г.Ж. Поликультурные аспекты образования. Казань: Отечество, 2017. 172 с.

Федоров и др., 2007 - Федоров А.В., Новикова А.А., Колеснченко В.Л, Каруна И.А. Медиаобразование в США, Канаде и Великобритании. Таганрог: изд-во Кучма, 2007.

Федоров, 2004 - Федоров А.В. Медиаобразование и медиаграмотность. Таганрог: Кучма, 2004. 340 с.

Федоров, 2010 - Федоров А.B. Словарь терминов по медиаобразованию, медиапедагогике, медиаграмотности, медиакомпетентности. Таганрог: Изд-во Таганрог. гос. пед. ин-та, 2010. 64 с.

Хилько, 2013 - Хилько Н.Ф. Формирование этнокультурной идентичности в процессе интеграции массового медиаобразования в поликультурный социум (методологические проблемы) // Медиаобразование. 2013. 1. [Электронный ресурс]. URL: http://cyberleninka.ru 
/article/n/formirovanie-etnokulturnoy-identichnosti-v-protsesse-integratsii-massovogo-mediaobrazo vaniya-v-polikulturnyy-sotsium

Челышева, 2019 - Челышева И.В. Методологические основы проблемы межэтнической толерантности студенческой молодежи в российском и англоязычном медиаобразовании постсоветского периода // Crede Experto: mpaнсnоpm, общество, образование, язык. 2019. 3. [Электронный ресурс]. URL: http://ce.if-mstuca.ru/wp-content/ uploads/2019/o3/Chelysheva-2_CE_2019-3.pdf

Чечет и др., 2014 - Чечет Т.И., Борисова Ю.В., Ионкина Е.Ю. Формирование критического мышления и толерантности как основных качеств личности в современном межнациональном пространстве при обучении иностранным языкам // Известия Волгоградского государственного технического университета. Серия: проблемы социально-гуманитарного знания, 2014. 24 (151): 151-154.

Чичерина, 2007 - Чичерина Н.B. Особенности восприятия и понимания медиатекста // Сибирский педагогический журнал, 2007. 9. [Electronic resource]. URL: https://cyber leninka.ru/article/n/osobennosti-vospriyatiya-i-ponimaniya-mediateksta

Chelysheva, Mikhaleva, 2019 - Chelysheva I., Mikhaleva G. Interethnic Tolerance Among University Students in the Context of Contemporary Russian and Foreign Media Education // Media Education (Mediaobrazovanie). 2019. 1: 14-22.

Recommendations..., 1999 - Recommendations Addressed to the United Nations Educational Scientific and Cultural Organization UNESCO. In: Education for the Media and the Digital Age. Vienna. UNESCO. 1999, pp. 273-274.

\section{References}

Chechet i dr., 2014 - Chechet, T.I., Borisova, Yu.V., Ionkina, E.Yu. (2014). Formirovanie kriticheskogo myshleniya i tolerantnosti kak osnovnykh kachestv lichnosti v sovremennom mezhnatsional'nom prostranstve pri obuchenii inostrannym yazykam [Formation of Critical Thinking and Tolerance as the Main Personality Qualities in the Present Interethnic Space by Foreign Languages Teaching]. Izvestiya Volgogradskogo gosudarstvennogo tekhnicheskogo universiteta. Seriya: problemy sotsial'no-gumanitarnogo znaniya. 24 (151): 151-154. [in Russian]

Chelysheva, 2019 - Chelysheva, I.V. (2019). Metodologicheskie osnovy problemy mezhetnicheskoi tolerantnosti studencheskoi molodezhi $\mathrm{v}$ rossiiskom i angloyazychnom mediaobrazovanii postsovetskogo perioda [Methodological foundations of the problem of interethnic tolerance of students in Russian and English-language media education of the postSoviet period]. Crede Experto: transport, obshchestvo, obrazovanie, yazyk. 3. [Elektronnyi resurs]. URL: http://ce.if-mstuca.ru/wp-content/ uploads/2019/o3/Chelysheva-2_CE_2019-3.pdf [in Russian]

Chelysheva, Mikhaleva, 2019 - Chelysheva, I., Mikhaleva, G. (2019). Interethnic Tolerance Among University Students in the Context of Contemporary Russian and Foreign Media Education. Media Education (Mediaobrazovanie). 1: 14-22.

Chicherina, 2007 - Chicherina, N.V. (2007). Osobennosti vospriyatiya i ponimaniya mediateksta [Features of the perception and understanding of media text]. Sibirskii pedagogicheskii zhurnal. 9. [Electronic resource]. URL: https://cyber leninka.ru/article/n/ osobennosti-vospriyatiya-i-ponimaniya-mediateksta [in Russian]

Fakhrutdinova, 2017 - Fakhrutdinova, G.Zh. (2017). Polikul'turnye aspekty obrazovaniya [Multicultural aspects of education]. Kazan': Otechestvo. 172 p. [in Russian]

Fedorov i dr., 2007 - Fedorov, A.V., Novikova, A.A., Kolesnchenko, V.L, Karuna, I.A. (2007). Mediaobrazovanie v SShA, Kanade i Velikobritanii [Media Education in the USA, Canada and Great Britain]. Taganrog: izd-vo Kuchma, 2007. [in Russian]

Fedorov, 2004 - Fedorov, A.V. (2004). Mediaobrazovanie i mediagramotnost' [Media education and media literacy]. Taganrog: Kuchma. 340 p. [in Russian]

Fedorov, 2010 - Fedorov, A.V. (2010). Slovar' terminov po mediaobrazovaniyu, mediapedagogike, mediagramotnosti, mediakompetentnosti [Glossary of terms on media education, media pedagogy, media literacy, media competence]. Taganrog: Izd-vo Taganrog. gos. ped. in-ta. 64 p. [in Russian]

Khil'ko, 2013 - Khil'ko, N.F. (2013). Formirovanie etnokul'turnoi identichnosti v protsesse integratsii massovogo mediaobrazovaniya v polikul'turnyi sotsium (metodologicheskie problemy) 
[The formation of ethnocultural identity in the process of integrating mass media education into a multicultural society (methodological problems)]. Mediaobrazovanie. 1. [Elektronnyi resurs]. URL: http://cyberleninka.ru /article/n/formirovanie-etnokulturnoy-identichnosti-v-protsesseintegratsii-massovogo-mediaobrazo vaniya-v-polikulturnyy-sotsium [in Russian]

Ponomareva, 1999 - Ponomareva, O.I. (1999). Formirovanie osnov etnopedagogicheskoi kul'tury budushchego uchitelya v polikul'turnom sotsiume [Laying the basis for Ethnopedagogical culture of the Intending Teacher in a Multicultural Society]. Avtoref. .... dis. k.p.n. M. 23 p. [in Russian]

Recommendations..., 1999 - Recommendations Addressed to the United Nations Educational Scientific and Cultural Organization UNESCO. In: Education for the Media and the Digital Age. Vienna. UNESCO. 1999, pp. 273-274.

Vinichenko, 2011 - Vinichenko, V.A. (2011). Formirovanie mezhetnicheskoi tolerantnosti u budushchikh spetsialistov po svyazyam s obshchestvennost'yu [Formation of Interethnic Tolerance among Future Public Relations Specialists]. Avtoref. .... dis. k.p.n. Irkutsk: Severo-Vostochnyi federal'nyi universitet. 20 p. [in Russian]

Zhmyrova, 2008 - Zhmyrova, E.Yu. (2008). Kinoiskusstvo kak sredstvo vospitaniya tolerantnosti u uchashcheisya molodezhi [Art of cinema as a means of development of tolerance]. Tambovskii universitet. Seriya: Gumanitarnye nauki, 2008. 3 (59): 303-306. [Electronic resource]. URL: https://cyberleninka.ru/ article/n/kino iskusstvo-kak-sredstvo-vospitaniya-tolerantnosti [in Russian]

\section{Изучение уровней восприятия аудиовизуальных медиатекстов межэтнической проблематики в студенческой аудитории}

Ирина Викториновна Челышева а, *

a Ростовский государственный экономический университет, Российская Федерация

Аннотация. В статье представлены результаты экспериментальной работы, направленной на диагностику уровней восприятия аудиовизуальных медиатекстов межэтнической проблематики в студенческой аудитории. Автор представляет основные теоретические подходы к этой проблеме, выделяет ключевые классификационные показатели для восприятия аудиовизуальных медийных текстов, а также анализирует диагностический материал по изучению уровней восприятия медиа аудиовизуальных медийных текстов по этническим вопросам.

Основными методологическими принципами исследования выступают: принцип единства теории и практики в исследовании проблемы межэтнической толерантности.

Ключевые слова: межэтническая толерантность, медиаобразование, медиа восприятие, студенты вузов, экспериментальная работа.

\footnotetext{
${ }^{*}$ Корреспондирующий автор

Адреса электронной почты: ivchelysheva@yandex.ru (И.В. Челышева)
} 